\title{
PENGARUH MODEL PEMBELAJARAN GROUP TO GROUP EXCHANGE TERHADAP KREATIVITAS DAN HASIL BELAJAR MATEMATIKA SISWA SMP
}

\author{
B Ediansyah Putra* \\ Program Studi Pendidikan Matematika, STKIP Bima \\ *Email korespondensi: yhandecoz@gmail.com
}

\begin{abstract}
ABSTRAK
Penelitian ini dilatarbelakangi oleh masih rendahnya kreativitas dan hasil belajar matematika siswa SMP 13 Negeri di Kota Bima. Adapun tujuan dari penelitian ini untuk membuktikan pengaruhn Model Pembelajaran Group to Group Exchange terhadap kreatifitas dan hasil belajar matematika siswa. Jenis penelitian yang digunakan dalam penelitian ini adalah quasi eksperimen, dikatakan begitu karena dalam desain ini peneliti tidak dapat mengontrol semua variabel luar yaitu faktor luar yang tidak diteliti dan menjadi pengganggu sehingga mempengaruhi jalannya eksperimen. Adapun hasil penelitian ini menunjukkan bahwa semua aspek yang dinilai muncul pada saat proses pembelajaran berlangsung. Hal tersebut dilengkapi dengan hasil uji statistik dengan hasil thitung lebih besar dari tabel yaitu 2,46>1,98 dengan perolehan nilai rata-rata hasil belajar kelas eksperimen lebih besar dari kelas kontrol yaitu $95>75$. Hal ini berarti bahwa model pembelajaran Group to Group Exchange memberikan hasil yang lebih baik dibandingkan dengan pembelajaran konvensional. Dengan demikian bahwa langkah-langkah model pembelajaran model pembelajaran Group to Group Exchange memberikan pengaruh dalam meningkatkan kreativitas dan hasil belajar matematika siswa.
\end{abstract}

Kata kunci: group to group exchange, kreativitas dan hasil belajar matematika.

\begin{abstract}
This research is motivated by the low creativity and mathematics learning outcomes of SMP 13 Negeri students in Bima City. The purpose of this study is to prove the influence of the Group to Group Exchange Learning Model on students' creativity and mathematics learning outcomes. The type of research used in this study is quasi-experimental, it is said that because in this design the researcher cannot control all external variables, namely external factors that are not examined and become a nuisance so that it affects the course of the experiment. The results of this study indicate that all aspects that are assessed appear during the learning process. This is complemented by the results of statistical tests with the results of tcount greater than table, namely 2.46 > 1.98 with the acquisition of the average value of learning outcomes for the experimental class greater than the control class, which is $95>75$. This means that the Group to learning model Group Exchange provides better results compared to conventional learning. Thus, the steps of the learning model of the Group to Group Exchange learning model have an effect on increasing students' creativity and mathematics learning outcomes.
\end{abstract}

Keywords: group to group exchange, learning outcomes and mathematical creativities. 


\section{PENDAHULUAN}

Pendidikan matematika merupakan salah satu program dalam upaya mencapai tujuan pendidikan nasional. Di era revolusi industri 4.0, kompleksitas dan semakin ketatnya persaingan dunia kerja memberikan tuntutan pada program pendidikan matematikau ntuk mampu mengembangkan lagi proses melalui kegiatan pembelajaran yang mampu menumbuhkembangkan kemampuan berpikir (Sowanto dkk, 2019). Lebih lanjut Mikrayanti (2020) menyatakan bahwa penguasaan terhadap matematika menjadi sarana yang ampuh dalam mempelajari bidang ilmu yang lain, baik pada jenjang pendidikan yang sama maupun pada jenjang yang lebih tinggi.

Dalam perspektif Pembangunan Pendidikan Nasional, pendidikan harus lebih berperan dalam membangun seluruh potensi manusia agar menjadi subyek yang berkembang secara optimal dan bermanfaat bagi masyarakat dan pembangunan nasional (Suryana, 2020). Keberhasilan pembelajaran apabila sebagian peserta didik terlibat secara aktif, baik fisik, mental maupun sosial dalam proses pembelajaran, di samping menunjukkan kegairahan belajar tingi, semangat belajar tinggi, rasa percaya diri pada diri sendiri (Mulyasa, 2009).

Rusman dalam Mutmainnah, Dusalan, \& Muchlis (2018) mengemukakan bahwa siswa memahami konsep dan prinsip dari suatu materi dimulai dari belajar dan belajar terhadap situasi atau masalah yang diberikan melalui investigasi, inquiry, dan pemecahan masalah. Lebih lanjut Silberman (2016) mengungkapkan dalam pembelajaran aktif peserta didik berupaya untuk mengajukan pertanyaan. Peserta didik yang mengajukan pertanyaan sendiri berarti peserta didik tersebut memiliki keingintahuan yang besar terhadap materi yang dipelajari. Siswa membangun konsep atau prinsip dengan kemampuannya sendiri yang mengintegrasikan keterampilan dan pengetahuan yang sudah dipahami sebelumnya.

Dalam rangka memfasiltiasi keberagaman kemampuan peserta didik, pemilihan model pembelajaran serta sistem penilaian oleh guru bukan merupakan hal yang mudah. Oleh karena itu, guru dituntut harus menciptakan proses pembelajaran yang inovatif dan kreatif yang mampu mengajarkan peserta didik untuk memahami pelajaran dengan mudah. Sebab terdapat korelasi positif antara keyakinan siswa terhadap materi pembelajaran dengan prestasi belajarnya sebagaimana yang diungkapkan oleh Fennema and Sherman dalam 
Kusumah (2018) yang menyatakan bahwa "belief in a person's ability to learn mathematics has been found to have a strong positive correlation with mathematical achievement". Oleh karena itu pembelajaran yang dirancang oleh guru hendaknya merupakan desain pembelajaran yag dapat membuat peserta didik berperan aktif dalam pembelajaran, agar pembelajaran lebih bermakna dan tujuan pembelajaran dapat tercapai dengan baik.

Salah satu alternatif yang bisa dipilih oleh guru adalah dengan model Group to Group Exchange (GGE). Menurut Prayogo dan Silviana (2010) tujuan penggunaan model Group to Group Exchange (GGE) adalah memungkinkan siswa belajar lebih aktif serta melatih tanggung jawab dan kepemimpinan pada diri siswa, siswa juga akan termotivasi dalam mengikuti kegiatan belajar dan semua siswa akan memperoleh banyak pengetahuan dan pengalaman. Kemudian dijelaskan juga bahwa melalui model Group to Group Exchange $(G G E)$ siswa mampu berinteraksi secara terbuka, berdialog, dan intreaktif dibawah bimbingan guru. Hal senada juga diungkapkan oleh Budimansyah (2009), Group to Group Exchange adalah salah satu teknik instruksional dari belajar aktif (active learning) yang termasuk dalam pembelajaran sesama siswa. Model pembelajaran ini memberi siswa kesempatan untuk mempelajari sesuatu dengan baik dan sekaligus menjadi sumber informasi bagi siswa lainnya.

\section{METODE PENELITIAN}

Jenis penelitian yang digunakan dalam penelitian ini adalah quasi eksperimen, dikatakan begitu karena dalam desain ini peneliti tidak dapat mengontrol semua variabel luar yaitu faktor luar yang tidak diteliti dan menjadi pengganggu sehingga mempengaruhi jalannya eksperimen. Pemilihan sampel penelitian ditentukan berdasarkan purposive sampling yaitu tehnik pengambilan sampel berdasarkan pertimbangan tertentu (Sugiyono, 2008). Tujuan dilakukan pengambilan sampel seperti ini adalah agar penelitian dapat dilaksanakan secara efektif dan efisien terutama dalam hal pengawasan kondisi subjek penelitian.

Pada penelitian ini, kelas eksperimen merupakan kelompok siswa yang mendapat pembelajaran dengan Group to Group Exchange dan kelas kontrol merupakan kelompok siswa yang mendapat pembelajaran biasa. Adanya kelas kontrol ini adalah sebagai pembanding, sejauh manakah terjadi perubahan akibat perlakuan terhadap kelas eksperimen. 
Adapun desain penelitian ini adalah sebagai berikut:

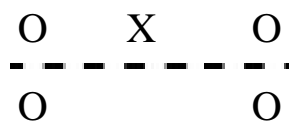

Keterangan:

$\mathrm{O} \quad$ : Pre-test atau post-test aktivitas dan hasil belajar matematika siswa

X : Pembelajaran dengan Group to Group Exchange

: Subjek penelitian tidak dikelompokkan secara acak.

Sampel pada penelitian ini hanya mengambil dua kelompok yaitu kelompok untuk kelas eksperimen dan kelompok untuk kelas kontrol. Dengan pertimbangan mendapatkan materi yang VIII/A sebagai kelas eksperimen dan VIII/B sebagai kelas kontrol. Instrumen pembelajaran yang digunakan dalam penelitian ini ada dua yaitu lembar observasi dan mode test.

\section{HASIL DAN PEMBAHASAN}

Penelitian ini menggunakan instrument berupa lembar observasi (angket) dan soal tes (essay). Sebelum tes digunakan terlebih dahulu harus diuji untuk mengetahui validitas, reabilitas, daya pembeda dan indeks kesukaran suatu tes. Selanjutnya sampel akan diberikan pre-test dan post-test untuk mengetahui adanya pengaruh model pembelajaran terhadap hasil belajar siswa melalui uji normalitas, uji homogenitas, dan uji hipotesis.

\section{Uji normalitas}

Perhitungan Uji normalitas menggunakan rumus Chi-Kuadrat sehingga diperoleh hasil yang tercantum pada Tabel 1 sebagai berikut :

Tabel 1. Nilai Chi Kuadrat ( $\chi 2)$ kelas eksperimen dan kelas control

\begin{tabular}{llll}
\hline \multicolumn{1}{c}{ Kelas } & \multicolumn{1}{c}{$\boldsymbol{x}^{2}$ hitung } & $\boldsymbol{x}^{2}$ tabel & distribusi \\
\hline Eksperimen pre tets & 6,03 & 7,82 & Normal \\
Eksperimen post test & 5,23 & 7,82 & Normal \\
Kontrol pre test & 5,7 & 7,82 & Normal \\
Kontrol post test & 3,56 & 7,82 & Normal \\
\hline
\end{tabular}


Berdasarkan tabel diatas maka hasil uji normalitas $\left(x_{\text {trtung }}^{2}\right)<\left(x^{2}{ }_{\text {Tabei }}\right)$, atau $\left(x_{\text {Tavel }}^{2}\right)>\left(x_{\text {Hteung }}^{2}\right)$. maka dapat disimpulkan data pre-test dan pos-ttest untuk kedua kelas tersebut Berdistribusi Normal.

\section{Uji Homogenitas}

Pengujian dilakukan dengan maksud untuk mengetahui apakah sebaran data homogen atau tidak. Kriteria pengujian yang dilakukan pada taraf signifikan 5\% (uji Fisher). Sampel akan dinyatakan homogen jika $\mathrm{F}_{\text {_hitung }}<\mathrm{F} \_$tabel. Berikut ini adalah hasil dari perhitungan uji Homogenitas yaitu :

Tabel 2. Nilai Uji Homogenitas kelas eksperimen dan kelas kontrol

\begin{tabular}{ccccc}
\hline & & $F$ (hitung) & $F$ (tabel) & Keterangan \\
\hline $\begin{array}{c}\text { Eksperimen } \\
\text { Kontrol }\end{array}$ & 195,1 & 1,9 & 2.11 & Homogen \\
\hline
\end{tabular}

Dari tabel diatas diperoleh $F_{\text {hiturg }}$ sebesar 1,87 dan $F_{\text {tabel }}$ sebesar 2,11 untuk data pretest. Berdasarkan hasil tersebut dapat disimpulkan bahwa kedua kelas berasal dari sampel yang homogen.

\section{Uji Hipotesis}

Hasil Perhitungan analisis nilai posttest kelompok kontrol dapat dilihat bahwa pada soal pre-test siswa mendapatkan nilai terendah 45 dan tertinggi 75 dengan nilai rata-rata 64 sedangkan pada soal post-test kelompok eksperimen mendapatkan nilai terendah 65 dan nilai tertinggi 95 dengan nilai rata-rata 83, dapat dilihat pada tabel berikut. Kemudian diperoleh hasil Uji hipotesis $\mathrm{t}_{\text {hitung }}=2,46$ dengan harga pada taraf signifikan 5\% untuk uji dua pihak dengan harga $t_{\text {tabel }}=1,67$. Selengkapnya dapat dilihat pada tabel di bawah ini.

Tabel 3. Hasil Observasi Aktivitas dan Hasil Evaluasi Belajar Siswa

\begin{tabular}{cccccccc}
\hline & \multicolumn{2}{c}{ Kreativtas Belajar } & \multicolumn{2}{c}{ Hasil Belajar Siswa } & Ketuntasan \\
\cline { 2 - 6 } Kelas & $\begin{array}{c}\text { Rata-rata } \\
\text { Skor }\end{array}$ & Kategori & $\begin{array}{c}\text { Nilai } \\
\text { Terendah }\end{array}$ & $\begin{array}{c}\text { Nilai } \\
\text { Tertinggi }\end{array}$ & $\begin{array}{c}\text { Nilai } \\
\text { Rata-rata }\end{array}$ & Belajar & Uj -t \\
\hline Eksperimen & 72,6 & Kreatif & 65 & 95 & 83,56 & $82 \%$ & 2,46 \\
Kontrol & 53,2 & Cukup & 45 & 75 & 64,35 & $64 \%$ & \\
\hline
\end{tabular}


Dari tabel diatas menunjukan bahwa nilai $\mathrm{t}_{\text {hitung }}>\mathrm{t}_{\text {tabel }}(2,46>1,98) \mathrm{H}_{0}$ ditolak dengan demikian $\mathrm{H}_{\mathrm{a}}$ diterima. Jadi dapat disimpulkan bahwa penggunaan model pembelajaran Group to Group Exchange berpengaruh dan signifikan terhadap hasil belajar siswa pada materi sistem persamaan linear tiga variabel. Hasil penilaian menunjukkan bahwa semua aspek yang dinilai muncul pada saat proses pembelajaran berlangsung. Hal tersebut menyatakan bahwa langkah-langkah model pembelajaran telah dilaksanakan dengan baik.

\section{Pembahasan}

Dalam pelaksanaan proses pembelajaran kelas eksperimen dengan menerapkan kombinasi strategi pembelajaran Group to Group Exchange siswa dikelompokkan dalam beberapa kelompok kecil. Dengan kata lain, proses pembelajaran menggunakan kombinasi strategi pembelajaran Group to Group Exchange sangat mengoptimalkan partisipasi siswa, sehingga siswa lebih memahami materi pelajaran dan hasil belajar yang diperolehpun akan meningkat. Pada proses pembelajaran setelah diberikan perlakuan, maka untuk kelas eksperimen dan kelas kontrol diberikan post-test yang bertujuan untuk mengetahui ada atau tidaknya pengaruh terhadap hasil belajar setelah diberikannya perlakuan. Pada penerapan kombinasi strategi pembelajaran Group to Group Exchange siswa dituntut aktif, secara maksimal melibatkan seluruh kemampuan peserta didik untuk mencari dan menyelidiki secara sistematis

\section{KESIMPULAN}

Adapun hasil penelitian ini menunjukkan bahwa semua aspek yang dinilai muncul pada saat proses pembelajaran berlangsung. Hal tersebut dilengkapi dengan hasil uji statistik dengan hasil thitung lebih besar dari ttabel yaitu 2,46>1,98 dengan perolehan nilai rata-rata hasil belajar kelas eksperimen lebih besar dari kelas kontrol yaitu $95>75$. Hal ini berarti bahwa model pembelajaran Group to Group Exchange memberikan hasil yang lebih baik dibandingkan dengan pembelajaran konvensional. Dengan demikian bahwa langkah-langkah model pembelajaran model pembelajaran Group to Group Exchange memberikan pengaruh dalam meningkatkan kreativitas dan hasil belajar matematika siswa. 


\section{REKOMENDASI}

Penelitian ini, diharapkan dapat berguna untuk kemajuan pendidikan khususnya dalam bidang pendidikan matematika. Guru dapat memadukan model pembelajaran Group to Group Exchange ini dengan model lain sesuai kebutuhan pembelajaran di dalam kelas sehingga materi dapat tersampaikan dengan baik dan menarik bagi siswa di kelas.

\section{UCAPAN TERIMAKASIH}

Ucapan terima kasih kepada pihak salah satu SMA Negeri tempat dilaksanakan penelitian di Kota Bima mulai dari kepala sekolah sampai guru-guru beserta staf yang telah banyak membantu dalam kegiatan penelitian yang dilakukan. Serta Pihak-pihak berkontribusi dalam diskusi atau pengolah data yang terkait langsung dengan penelitian/penulisan.

\section{REFERENSI}

Budimansyah, D. (2009). PAIKEM (Pembelajaran Aktif, Kreatif, Efektif, dan Menyenangkan). Bandung: Ganesindo

Kusumah, Y. S. (2018, May). Enhancing students' mathematical representation and selfefficacy through situation-based learning assisted by geometer's sketchpad program. In Journal of Physics: Conference Series (Vol. 1013, No. 1, p. 012107). IOP Publishing.

MIKRAYANTI, M. (2020). PENGARUH PEMBELAJARAN KOOPERATIF TIPE JIGSAW TERHADAP PENINGKATAN HASIL BELAJAR SISWA. SUPERMAT (Jurnal Pendidikan Matematika), 4(1), 33-39.

Mulyasa, E. (2009). Menjadi Guru Profesional. Bandung: PT Remaja Rosdakarya.

Mutmainah, M., Dusalan, D., \& Muchlis, M. (2018). Pengaruh Pembelajaranproblem Based Learning Terhadap Kreativitas Matematikasiswa Pada Kelas Viii Unggulan Mtsn 1 Makassar.Supermat(Jurnal Pendidikan Matematika),2(2), 18-28.

Prayogo dan Silviana, A. (2010). Upaya Meningkatkan Prestasi Belajar Matematika Siswa dengan Pembelajaran Aktif Menggunakan Strategi Group to Group Exchange Melalui Bantuan Tutor Sebaya di Kelas X SMA Muhammadiyah 5 Karanggeneng Lamongan. 
Jurnal Semnas. Pendidikan Matematika dan Statistika UNIPA. Surabaya: Tidak diterbitkan

Silberman, Melvin L. (2016). Active learning 101 Cara Belajar Siswa Aktif. (alih bahasa : Raisul Muttaqien). Bandung: Nuansa Cendekia

Sowanto, S., Andang, A., Mutmainnah, M., \& Saputra, H. A. (2019). Kemampuan SelfEfficacy Mahasiswa Melalui Bahan Ajar Metode Statistika Menggunakan Hybrid Learning Pada Tantangan Revolusi Industri 4.0. Supermat (jurnal pendidikan matematika), 3(2), 65-73.

Sugiyono. (2008). Metode penelitian pendidikan:(pendekatan kuantitatif, kualitatif dan R \&D). Bandung: Alfabeta.

Suryana, S. (2020). Permasalahan mutu pendidikan dalam perspektif pembangunan pendidikan. Edukasi, 14(1). 